\title{
Equilibrium, Kinetics and Thermodynamic Studies for Adsorption of CR (VI) onto Natural Adsorbents
}

\author{
S.Bhuvaneshwari $^{1}$, N.Mohanraj ${ }^{2}$, Murugan $^{3}$, Dr.V.Sivasubramanian ${ }^{4}$ \\ Department of Chemical Engineering, National Institute of Technology, Calicut, Kerala, India ${ }^{1,2,3}$ \\ Associate Professor, Chemical Engineering Department, National Institute of Technology, Calicut, Kerala, India ${ }^{4}$
}

\begin{abstract}
The study on the performance of natural adsorbents like chitosan saw dust and tea waste in the removal of chromium ion $(\mathrm{Cr}(\mathrm{VI}))$ from wastewater has been performed in batch mode. The effects of pH, adsorbent concentration, $\mathrm{Cr}$ (VI) concentration, contact time and shaking speed were studied on the removal of $\mathrm{Cr}$ (VI) from synthetic wastewater. A comparative study has been done on the adsorption capacities of the three adsorbents for $\mathrm{Cr}$ (VI) adsorption. The highest adsorption capacity of $99.257 \%$ has been observed with chitosan as adsorbent at optimized conditions. The equilibrium data for the batch adsorption of $\mathrm{Cr}$ (VI) onto natural adsorbents have been tested with Langmuir, Freundlich, BET and Dubinin-Radushkevich isotherm models. The mechanism of Cr (VI) sorption by chitosan gave good fits with the Langmuir model with a maximum adsorption capacity of $35.7 \mathrm{mg} / \mathrm{g}$. It has been found that the kinetics of $\mathrm{Cr}$ (VI) adsorption onto chitosan can be explained well by the pseudo second order kinetic model. Desorption of $\mathrm{Cr}(\mathrm{VI})$ ions from the metal loaded chitosan was maximum at $0.1 \mathrm{M}$ of $\mathrm{H}_{2} \mathrm{SO}_{4}$ with an agitation speed of $120 \mathrm{rpm}$ and a contact time of 60 minutes. A multiple response method, using the design expert software 8.0.6.1 was applied for optimization of adsorbent dosage, $\mathrm{Cr}$ (VI) concentration, contact time, agitation speed \% adsorption and \% desorption.
\end{abstract}

Key words: $\mathrm{Cr}$ (VI) adsorption, chitosan, isotherm, kinetics, saw dust and tea waste.

\section{INTRODUCTION}

Water is a unique substance, because it can naturally renew and cleanse itself, by allowing pollutants to settle out or break down, or by diluting the pollutants to a point where they are not in harmful concentrations. However, this natural process takes time, and is difficult when excessive quantities of harmful contaminants are added to the water ${ }^{[1]}$. Industrial activities are responsible for the discharge of waste into the environment, most of which contain toxic and hazardous substances that are detrimental to human health. Heavy metals are major toxicants found in industrial wastewaters; they may adversely affect the quality of water ${ }^{[2]}$. Chromium is a heavy metal, whose compounds are considered to be highly toxic to humans. $\mathrm{Cr}$ (VI) is generally produced by industrial processes, due to its toxicity and suspected carcinogenicity, however, chromium is heavily regulated to human health and the environment ${ }^{[3],[4]}$. Conventional physico-chemical treatment methods for removing heavy metals from the waste streams include precipitation, filtration, oxidation-reduction, ion exchange and membrane separation. However, when metals are dissolved in huge volumes in relatively low concentrations, these methods become generally ineffective or expensive ${ }^{[5]}$.Thus, there is a need for cheaper methods for effluent treatment.

Among the different physicochemical treatments being employed for wastewater treatment, adsorption technique has been found to be very effective to treat effluents with high loadings of contaminants at dilute concentrations typically $<100 \mathrm{mg} / \mathrm{L}$. various functional groups such as carboxyl, hydroxyl, amino and phosphate existing on the adsorbents can subsequently bind the heavy metals ${ }^{[6]}$. A variety of natural materials like agriculture waste, marine organism and micro organisms have been successfully used as adsorbents for the removal of heavy metals ${ }^{6}$. Biosorption is a process that utilizes biological/natural materials as adsorbents. This method has been studied by several researchers as an alternative technique to conventional methods for heavy metal removal from wastewater ${ }^{[7]}$. The binding mechanisms of heavy metals by biosorption could be explained by the physical and chemical interactions, ion exchange, complexation, coordination and micro precipitation. The diffusion of the metal from the bulk solution to the active sites of adsorbents occurs predominantly through passive transport mechanisms ${ }^{[8] .}$

Chitosan displays the basic properties that impart it with unique physico-chemical characteristics. It is an excellent chelating agent for removing heavy toxic metals from sewage ${ }^{[9]}$. The amino group is responsible for the polycationic character of chitosan, and for the formation of the well-known intermolecular complexes with carboxylic and polycarboxylic acids ${ }^{[10]}$. Metal adsorption is a rather complex process and affected by several other factors too [11]. The major advantages of using natural adsorbents include: low cost, high efficiency regeneration of adsorbent and the possibility of metal recovery ${ }^{[12-14]}$.

One- third of the total dry matter in tea leaves should have good potential as metal scavengers from solutions and waste waters since the above constituents contain functional groups. The responsible groups in lignin, tannin or other phenolic compounds are mainly carboxylate, 
aromatic carboxylate, phenolic hydroxyl and oxyl groups

${ }^{[15]}$. The feasibility of tea waste as an adsorbent for the removal of chromium in fixed bed was studied elsewhere andindicated that the tea waste can be used as an effective and environment friendly adsorbent for the treatment of chromium in aqueous solutions ${ }^{[16]}$. Sawdust contains water-soluble compounds like tannin, which is again responsible for hydroxyl and carboxylic group on chemical treatment ${ }^{[17]}$.Sawdust provides cationic active sites (i.e., amino groups) and enhances the substantively of wood cellulose for anionic metals.

The batch studies for the adsorption of $\mathrm{Cr}(\mathrm{VI})$ from synthetic wastewater are being influenced by the operating conditions such as temperature, $\mathrm{pH}$, adsorbent dose ,initial metal concentrations, contact time and agitation speed ${ }^{[18]}$. The Response surface methodology (RSM) is a collection of mathematical and statistical techniques has an important application in the process design and optimization, as well as in the improvement of the existing design ${ }^{[19-20]}$.

Based on the comprehensive review of literature, the present study was undertaken with the following objectives:

1. To do experimental and theoretical investigation on adsorption of $\mathrm{Cr}$ (VI) from aqueous waste water solutions using naturally available adsorbents (Chitosan, Saw dust and Tea waste).

2. To identify the effective adsorbent among the three for $\mathrm{Cr}$ (VI) adsorption.

3. To study the isotherm, kinetics and thermodynamic effect on $\mathrm{Cr}$ (VI) adsorption at batch operations.

4. Non-destructive recovery of heavy metals by certain potential desorbing agents and to regenerate the adsorbent material for another cycle of application.

5. To do modeling and simulation approach to validate the experimental results using response surface methodology (RSM).

\section{MATERIALS AND METHODS}

\section{MATERIALS USED}

All the chemicals used are of analytical grade and samples were prepared using double distilled water.

\section{Synthetic metal solution}

Synthetic wastewater containing $\mathrm{Cr}$ (VI) was prepared by adding $2.8287 \mathrm{~g}$ of potassium dichromate $\left(\mathrm{K}_{2} \mathrm{Cr}_{2} \mathrm{O}_{7}\right)$ in $1000 \mathrm{ml}$ of deionized water i.e. $1000 \mathrm{ppm}$ chromium solution. $1 \mathrm{ml}$ of the standard solution was dissolved in $100 \mathrm{ml}$ distilled water to make $10 \mathrm{ppm}$ solution. This solution was further mixed in the ratio $2: 8,4: 6,6: 4,8: 2$ with distilled water to form $2,4,6,8 \mathrm{ppm}$ solutions respectively.

\section{Adsorbents}

The adsorbents used for the present experiments are saw dust, tea waste and chitosan.

\section{Saw dust}

Saw dust was taken from the carpentry workshop. It was screened through BSS 25 mesh for uniform sized particle. It was washed thoroughly using distilled water and dried in an oven at $80^{\circ} \mathrm{C}$ for duration of 4 hours.

\section{Chitosan}

Chitosan is obtained from the deacetylation of chitin. Chitin is one of the most abundantly available polymers after cellulose. Present experiments were carried out using pelletized form of chitosan (donated by Cochin Institute of Fisheries Technology, Cochin). CIFT has developed an efficient and economical technology to produce chitin and chitosan from this shrimp waste, process for the production involves de-proteinisation and demineralization of shrimp shell by which chitin is produced and then converted to chitosan by deacetylation.

Tea waste

Tea powder was boiled at $60{ }^{0} \mathrm{C}$ for 15 minutes and then filtered; the tea residue left over the whatmann no 1 filter paper was dried at $80{ }^{0} \mathrm{C}$ for 90 minutes and used as adsorbent.

\section{Instrumentation}

The residual metallic ion concentrations were determined using an Atomic Absorption Spectrophotometer (AAS), Thermo scientific AA 303.Centrifugation and filtration were done before atomic adsorption measurements to remove suspended particles and thus to avoid turbidity problems. FTIR spectra were recorded on a Thermo Nicolet Model-Avater 320 FTIR spectrophotometer. The surface morphology of adsorbents was examined using a Scanning Electron Microscope, (HITACHI SU 6600 Japan).

\section{EXPERIMENTAL METHODS}

The experiments in this work were divided into two parts. The first part of the study was aimed at investigating the effect of experimental conditions on $\mathrm{Cr}$ (VI) adsorption from synthetic $\mathrm{Cr}$ (VI) solutions using naturally available adsorbents like chitosan, saw dust and tea waste and determining the conditions that achieve the maximum amount of chromium removal. The second part of the study examined the desorption efficacy. Studies were done in detail to regenerate the adsorbent effectively for reuse. Isotherm, kinetic and thermodynamic parameters were evaluated. Modeling and optimization were done using RSM.

Batch adsorption studies: Adsorption tests of $\mathrm{Cr}$ (VI) on chitosan obtained from shrimp shells and other adsorbents like tea waste and saw dust were carried out at different metal concentration, biosorbent concentration, contact time, shaking speed, $\mathrm{pH}$ and temperature. Borosil glass conical flasks of $250 \mathrm{ml}$ capacity with $50 \mathrm{ml}$ of synthetic and industrial wastewater of desired concentrations and $\mathrm{pH}$ were used. Adsorbents were added as per dose requirements and subsequently the flasks were shaken at a constant $\mathrm{rpm}$ in an incubator. The flasks were taken out from the shaker at pre-determined intervals and the content was filtered using Whatman No. 1 filter paper. The filtrate containing the residual $\mathrm{Cr}$ (VI) was analyzed using an atomic absorption spectrophotometer ${ }^{[21]}$. The amount of $\mathrm{Cr}(\mathrm{VI})$ removed by the biosorbent was calculated using $\mathrm{Eq}(1)$

$$
\operatorname{MetalRemoval}(\%)=\left(\frac{\mathrm{C}_{\text {in }}-\mathrm{C}_{\mathrm{o}}}{\mathrm{C}_{\text {in }}}\right) \times 100
$$




\section{CHITOSAN AS ADSORBENT}

Batch experiments were carried out in different sets by taking chitosan in the range of $0.2-1.4 \mathrm{~g} / \mathrm{l}$ of synthetic $\mathrm{Cr}$ (VI) solution for a varying initial $\mathrm{Cr}(\mathrm{VI})$ concentration (2$10 \mathrm{mg} / \mathrm{l})$ in a series of conical flasks at a varying $\mathrm{pH}(2-$ $10)$, varying shaking time (30- $240 \mathrm{~min})$ and shaking speed (30 -150 rpm) in an incubator shaker. Samples were collected at different time intervals and analyzed using AAS for $\mathrm{Cr}$ (VI) concentration. And determined the optimum conditions that achieve the maximum amount of chromium removal.

\section{SAW DUST AS ADSORBENT}

Batch experiments were repeated in different sets by taking saw dust in the range of $0.5-4 \mathrm{~g}$ in $50 \mathrm{ml}$ of synthetic $\mathrm{Cr}$ (VI) solution of desired initial $\mathrm{Cr}$ (VI) concentration $(6 \mathrm{mg} / \mathrm{l})$ in a series of conical flasks at a varying $\mathrm{pH}$ (2-8), varying shaking time (30- $480 \mathrm{~min}$ ) and shaking speed (30 -150 rpm) in an incubator shaker. Samples were collected at different time intervals and analyzed using AAS for $\mathrm{Cr}$ (VI) concentration. And determined the optimum conditions that achieve the maximum amount of chromium removal.

\section{TEA WASTE AS ADSORBENT}

Batch experiments were repeated again in different sets by taking tea waste in the range of $0.5-40 \mathrm{~g} / \mathrm{l}$ of synthetic $\mathrm{Cr}$ (VI) solution of desired initial $\mathrm{Cr}$ (VI) concentration (6 $\mathrm{mg} / \mathrm{l})$ in a series of conical flasks at a varying $\mathrm{pH}(3-9)$, varying shaking time (30- $240 \mathrm{~min}$ ) and shaking speed (30 $-150 \mathrm{rpm})$ in an incubator shaker. Samples were collected at different time intervals and analyzed using AAS for $\mathrm{Cr}$ (VI) concentration. And determined the optimum conditions that achieve the maximum amount of chromium removal.

On comparing the $\mathrm{Cr}$ (VI) adsorption capability of the three adsorbents. Chitosan had the maximum adsorption capacity for $\mathrm{Cr}$ (VI). So the desorption experiments were conducted for metal loaded chitosan.

\section{EQUILIBRIUM, THERMODYNAMICS AND KINETICS STUDIES FOR ADSORPTION OF $\mathrm{Cr}$ (VI)}

Equilibrium studies were carried out to determine the conditions for maximum $\mathrm{Cr}$ (VI) removal onto chitosan. It was observed that adsorption capacity reaches an equilibrium value beyond which there was negligible change in the residual $\mathrm{Cr}$ (VI) concentration. The distribution of $\mathrm{Cr}$ (VI) between the liquid phase and the solid phase is a measure of the position of equilibrium in the adsorption process.

The quantity of adsorbate that can be taken up by adsorbent is a function of both the characteristics and concentration of adsorbate and the temperature. The amount of material adsorbed is determined as a function of concentration at a constant temperature; the resulting function is called an adsorption isotherm. The analysis of the isotherm data is of particular importance to develop an equation which accurately represents the results and could be used for design purpose.
In this study, the experimental data of $\mathrm{Cr}$ (VI) adsorption onto natural adsorbents (Chitosan, saw dust and tea waste) were fitted to the Langmuir, Freundlich, BET and Dubinin-Radushkevich isotherm models. Adsorption isotherms known as equilibrium data are the fundamental requirements for the design of adsorption systems ${ }^{[22-23]}$. The linear form of Langmuir, Freundlich, BET and Dubinin-Radushkevich isotherm equation along with their inference are illustrated in Table.1.

\section{ADSORPTION DYNAMICS}

The study of adsorption dynamics describes the solute uptake rate and evidently this controls the residence time of adsorbate uptake at the solid-solution interface. The kinetics of $\mathrm{Cr}(\mathrm{VI})$ adsorption onto natural adsorbents (chitosan, saw dust and tea waste) was analyzed using the pseudo first order, pseudo second order and Elovich and intra particle diffusion models ${ }^{[27]}$. The conformity between the experimental data and the model values has been expressed by the correlation coefficients $\left(\mathrm{R}^{2}\right.$, values closer or equal to 1). The linear form of pseudo first order, pseudo second order, Elovich and intra particle diffusion models along with their inference are illustrated in Table. 2

\section{Thermodynamic Parameters of Adsorption}

The thermodynamic parameters that must be considered to determine the process, enthalpy of adsorption $(\Delta \mathrm{H})$, free energy change $(\Delta G)$ and entropy change $(\Delta S)$ due to transfer of unit mole of solute from solution onto the solid-liquid interface ${ }^{[30]}$.

A negative enthalpy $(\Delta \mathrm{H})$ indicates that the adsorption process is exothermic. Decrease in adsorption with rise in temperature may be due to weakening of adsorptive forces between the active sites of adsorbent and adsorbate species and also between the adjacent molecules of the adsorbed phase. A negative change in entropy $(\Delta S)$ indicates that the biosorption is stable, as there is increase in orderliness of the system, which is at the aqueous metal ion- solid biosorbent interface. In general, negative values of $\Delta G$ show the feasibility and spontaneous nature of the sorption. A positive $\Delta \mathrm{H}$ indicates endothermic reaction. A positive change in entropy is an indication of increase in randomness at the solid-liquid interface.

Batch desorption studies: The desorption studies were carried out using the metal loaded adsorbents obtained after adsorption studies. The desorption tests were conducted in $250 \mathrm{ml}$ flask with $50 \mathrm{ml}$ of synthetic eluants like dilute mineral acids $\left(\mathrm{H}_{2} \mathrm{SO}_{4}\right.$ and $\mathrm{HCl}$ ), complexing agent (EDTA) and organic acids (ace tic acid and citric acid ) at different concentrations ranging from $0.001 \mathrm{M}$ to $0.1 \mathrm{M}^{[31]}$. The effect of temperature, contact time and shaking speed were studied in detail. In the tests, a given mass of metal loaded adsorbent (chitosan) was added to the solution and the resultant suspensions were shaken at a constant rpm for a specified amount of time. Upon completion a sample of the suspension was filtered through a whatmann No 1 filter and the filtrate was analyzed for residual Cr (VI) using the AAS. And the adsorbent (chitosan) regenerated was washed successively with distilled water and dried to initiate another cycle. The absence of a noticeable 
change in the desorption capacities of the reused chitosan confirms the reusable potential of chitosan.

Metal present in biosorbent after desorption $\left(\mathrm{q}_{\mathrm{d}}, \mathrm{mg} / \mathrm{g}\right)=\frac{\mathrm{Vx} \mathrm{C}_{\mathrm{f}}}{\mathrm{m}}$

Development of mathematical model using RSM:

Modeling and optimization of the experiments were done using RSM to validate the experimental results. Where the effects of test variable alone and/or in combination on the processes were analyzed and generated a methodology for mathematical model. The graphical perspective of mathematical model has been derived using the contour plots. Simulations were used to explore the performance of systems for analytical solutions.

The mathematical-statistical significance of the quadratic model was evaluated by the analysis of variance (ANOVA). This batch studies employed three test variables adsorbent dosage $\left(\mathrm{x}_{1}\right)$, metal concentration $\left(\mathrm{x}_{2}\right)$ and $\mathrm{pH}\left(\mathrm{x}_{3}\right)$, following the second-order polynomial equation:

$$
\begin{aligned}
& y=\alpha_{0}+\alpha_{1} x_{1}+\alpha_{2} x_{2}+\alpha_{3} x_{3}+\alpha_{1} \alpha_{2} x_{1} x_{2} \\
& +\alpha_{1} \alpha_{1} x_{1} x_{1}+\alpha_{2} \alpha_{2} x_{2} x_{2}+\alpha_{3} \alpha_{3} x_{3} x_{3}+\varepsilon
\end{aligned}
$$

\section{Optimization}

Optimization studies for the adsorption of $\mathrm{Cr}$ (VI) from synthetic Cr (VI) solutions were carried out by studying the effect of variables including adsorbent dosage, initial $\mathrm{Cr}$ (VI) ion concentrations, $\mathrm{pH}$ of solutions, shaking time and shaking speed by means of a central composite design (CCD) using RSM ${ }^{[32]}$.

\section{RESULTSAND DISCUSSION}

Effect of pH and mechanism of $\mathrm{Cr}$ (VI) adsorption onto chitosan

The results of batch studies on the effect of initial $\mathrm{pH}$ on $\mathrm{Cr}$ (VI) removal over a range of 2-10, showed $96.02 \%$ of $\mathrm{Cr}$ (VI) removal at a $\mathrm{pH}$ of 4 (initial $\mathrm{Cr}$ (VI) concentration $=6 \mathrm{mg} / \mathrm{l}$ and the corresponding optimum dose of chitosan $=50 \mathrm{mg}$ ). However, above $\mathrm{pH} 5$ there was a decrease in the uptake and the removal was found to be $74.2 \%$ at a $\mathrm{pH}$ of 10 (Fig.1). With increase in $\mathrm{pH}$ from 4 to 10, the degree of protonation of the adsorbent functional group decreased gradually and hence removal was decreased ${ }^{[33]}$. The experiments were repeated for varying adsorbent dosage (10-70 mg), contact time (30-240 min) and at different temperatures $\left(30-60{ }^{0} \mathrm{C}\right)$ to attain the maximum amount of chromium removal (Fig.1). The maximum removal of $99.257 \%$ was achieved under optimized conditions. Isotherm studies were conducted with an initial chitosan concentration of $0.2-1.4 \mathrm{~g} / \mathrm{l}$. The mechanism of $\mathrm{Cr}$ (VI) sorption by chitosan gave good fits with the Langmuir and Freundlich models with a maximum q value of $35.7 \mathrm{mg} / \mathrm{g}$. It has been found that the kinetics of $\mathrm{Cr}$ (VI) adsorption onto chitosan can be explained well by the pseudo second order kinetic model with $\mathrm{R}^{2}=0.999$ as illustrated in Fig.2, Fig.3, Table 3 \& Table 4.

Effect of pH and mechanism of $\mathrm{Cr}$ (VI) adsorption onto saw dust

Adsorption studies were conducted with an initial saw dust dosage concentration of $0.5-4.0 \mathrm{~g}$ per $50 \mathrm{ml}$ of synthetic $\mathrm{Cr}$ (VI) solutions. Results revealed that increase of saw dust dose from $0.5 \mathrm{~g}$ to $2 \mathrm{~g}$ increased the $\mathrm{Cr}$ (VI) adsorption from $2.15 \%$ to $52.13 \%$ after 60 min of equilibration (Fig.4). The results on the effect of initial $\mathrm{pH}$ on $\mathrm{Cr}$ (VI) removal over a range of $2-8$, showed $59.34 \%$ of $\mathrm{Cr}$ (VI) removal at a $\mathrm{pH}$ of 5 and the corresponding optimum dose of saw dust $=2 \mathrm{~g}$. However, above $\mathrm{pH} 5$ there was a decrease in the uptake and the removal was found to be $51.07 \%$ at a pH of 8 (Fig.4). Decrease in the $\mathrm{Cr}$ (VI) removal at a $\mathrm{pH}$ above and below 5 can be explained by the rapid changes in chemical nature of saw dust ${ }^{[34]}$. The experiments were repeated for varying contact time (30-480 min) and shaking speed (30-150 $\mathrm{rpm})$ to attain the maximum amount of chromium removal. The maximum removal of $67.33 \%$ was achieved under optimized conditions. Kinetic and isotherm modeling studies demonstrated that the experimental data best fit a pseudo second order and Freundlich model with the maximum adsorption capacity of $0.04 \mathrm{mg} / \mathrm{g}$, as illustrated in Table 3 \& Table 4.

\section{Effect of pH and mechanism of $\mathrm{Cr}$ (VI) adsorption onto tea waste}

Adsorption studies were conducted with an initial dosage concentration of $25 \mathrm{mg}-2000 \mathrm{mg}$ per $50 \mathrm{ml}$ of synthetic $\mathrm{Cr}$ (VI) solutions. Results revealed that increase of tea waste dose from $25 \mathrm{mg}$ to $500 \mathrm{mg}$ increased the $\mathrm{Cr}$ (VI) adsorption from $33.6 \%$ to $88.53 \%$ after $60 \mathrm{~min}$ of equilibration (Fig.5). The results on the effect of initial $\mathrm{pH}$ on $\mathrm{Cr}$ (VI) removal over a range of 3-9, showed $95.0 \%$ of $\mathrm{Cr}$ (VI) removal at a $\mathrm{pH}$ of 3 and the corresponding optimum dose of tea waste $=500 \mathrm{mg}$. However, above $\mathrm{pH}$ 3 there was a decrease in the uptake and the removal was found to be $86.5 \%$ at a pH of 9 (Fig.5). The experiments were repeated for varying contact time (30-240 $\mathrm{min}$ ) and at different temperatures $\left(30-50{ }^{\circ} \mathrm{C}\right)$ to attain the maximum amount of chromium removal. The maximum removal of $98.88 \%$ was achieved under optimized conditions. Kinetic and isotherm modeling studies demonstrated that the experimental data best fit a pseudo second order and Freundlich model with the maximum adsorption capacity of $0.097 \mathrm{mg} / \mathrm{g}$, as illustrated in Table $3 \&$ Table 4.

The energy of sorption was below $20.0 \mathrm{KJ} / \mathrm{mol}$ as per Dubinin-Radushkevich expression, confirms the adsorption was physical nature (physisorption) for the aforementioned experiments (Fig.6). And the value of D is sufficiently higher that $10^{-10} \mathrm{~m}^{2} / \mathrm{min}$ for all the three adsorbents concludes that pore diffusion is not the main rate determining step and the Table 5 points out clearly that the external diffusion cannot be neglected since all the $\mathrm{t}^{0.5}$ are greater than 1 . Hence it is appropriate to assume that the $\mathrm{Cr}(\mathrm{VI})$ adsorption is controlled by external mass transfer at earlier stages and by intra particle diffusion at later stages ${ }^{[35]}$.

\section{Thermodynamic Studies}

Thermodynamic studies were done by carrying out equilibrium studies at various temperatures to obtain corresponding values of $\mathrm{Ca}$ and $\mathrm{Ce}$.

$$
\mathrm{K}=\frac{\mathrm{C}_{\mathrm{a}}}{\mathrm{C}_{\mathrm{e}}}
$$


Where, Ca represents adsorption in $\mathrm{mg} / \mathrm{l}$ at equilibrium; terms are significant. In this case $\alpha_{2}, \alpha_{3}, \alpha_{1} \alpha_{2}, \alpha_{2}{ }^{2}, \alpha_{3}{ }^{2}$ $\mathrm{Ce}$ is the equilibrium concentration of the metal in $\mathrm{mg} / \mathrm{l} ; \mathrm{K}$ are significant model terms. The fit of the model was represents the thermodynamic equilibrium constant. checked by the determination of coefficient $\left(\mathrm{R}^{2}\right)$. In this The Gibb's free energy $\Delta G$ is related to the case, the value of the determination coefficient $\left(\mathrm{R}^{2}=\right.$ thermodynamic equilibrium constant by the following:

$$
\Delta \mathrm{G}=-\mathrm{R} \mathrm{T} \ln \mathrm{K}
$$

where, $\Delta \mathrm{G}$ is the Gibb's free energy in $\mathrm{J} / \mathrm{mole}$; $\mathrm{R}$ is the ideal gas constant whose value is $8.314 \mathrm{~J} / \mathrm{molK}$; $\mathrm{K}$ represents the thermodynamic equilibrium constant, $\mathrm{T}$ is temperature in Kelvin.

In thermodynamics, the Gibb's free energy is related to the enthalpy change $(\Delta H)$ and entropy change $(\Delta S)$ at constant temperature by the following van't Hoff equations:

$$
\ln \mathrm{K}=-\left(\frac{\Delta \mathrm{H}}{\mathrm{R} \mathrm{T}}\right)+\frac{\Delta \mathrm{S}}{\mathrm{R}}
$$

where, $\Delta \mathrm{H}$ stands for enthalpy change in $\mathrm{J} / \mathrm{mol}$; $\Delta \mathrm{S}$ represents entropy change in $\mathrm{J} / \mathrm{molK}$;

The values of $\Delta \mathrm{H}$ and $\Delta \mathrm{S}$ are obtained from the slopes and intercepts, respectively, of the plot of $\operatorname{lnK}$ against $1 / \mathrm{T}$.

Negative enthalpy $\Delta \mathrm{H}$ and $\Delta \mathrm{S}$ was obtained in thermodynamic study which indicates that the adsorption is exothermic and stable as there is increase in orderliness of the system ${ }^{[36]}$ (Table $6 \&$ Fig.7).

\section{DESORPTION OF CR (VI) FROM METAL LOADED CHITOSAN}

A maximum desorption $(88 \%)$ of $\mathrm{Cr}(\mathrm{VI})$ from chitosan was achieved under optimized conditions of contact time (60 min), agitation speed (120 rpm) and temperature $\left(40^{\circ} \mathrm{C}\right)$. Desorption was well described in all the cases studied. Adsorption efficiency remained the same for regenerated adsorbent ${ }^{[37]}$. The results confirm that environmental pollution due to chromium can be minimized to a larger extent.

\section{MODELING AND OPTIMIZATION}

\section{Model fitting:}

The empirical relationship for $\%$ metal removal ( $\%$ adsorption) (Y) versus the three test variables in coded units obtained by the application of RSM is given by

$$
\begin{aligned}
& \text { \% Metal removal }=+99.20-117.73 \mathrm{X}_{1}-11.738 \mathrm{X}_{2}+36.31 \mathrm{X}_{3} \\
& +18.28 \mathrm{X}_{1} \mathrm{X}_{2}+5.77 \mathrm{X}_{1}{ }^{2}-0.228 \mathrm{X}_{2}^{2}-4.05 \mathrm{X}_{3}^{2}
\end{aligned}
$$

where $y$ (response) is the $\%$ metal removal (\% adsorption ), $\mathrm{x}_{1}, \mathrm{x}_{2}$ and $\mathrm{x}_{3}$ are the coded values of the tests variables, adsorbent dosage $\left(\mathrm{x}_{1}\right)$, metal concentration $\left(\mathrm{x}_{2}\right)$ and $\mathrm{pH}$ $\left(\mathrm{x}_{3}\right)$. Polynomial regression analysis has been conducted for second-order response surface model and the results are given in Table 7.

The results of the \% Metal removal as a function of the independent variables adsorbent dosage, metal concentration and $\mathrm{pH}$ showed that this regression is statistically significant The Model F-value of 35.52 implies that there is only a $0.01 \%$ chance that a "Model FValue" is not significant this could occur due to noise. Values of "Prob > F" less than 0.0500 indicate model 0.9540 ) indicates that $4.6 \%$ of the total variable is not explained by the model. "Adeq Precision" measures the signal to noise ratio. A ratio greater than 4 is desirable. The ratio of 24.112 indicates an adequate signal. This model can be used to navigate the design space. The Response surface and contour plots for \% Metal removal are shown in Fig. 8.

\section{Optimization using Desirability Functions}

A multiple response method was applied for optimization of adsorbent dosage, $\mathrm{Cr}$ (VI) concentration, contact time, agitation speed and adsorption (\%). Numerical optimization found a point that maximizes the desirability function. A minimum level of adsorbent (chitosan) dosage (25.27 mg), agitation speed (69.88 rpm), a maximum level of initial $\mathrm{Cr}(\mathrm{VI})$ concentration $(8.18 \mathrm{mg} / \mathrm{l})$ and shaking time (103.82 min) resulted in $99.3 \%$ of $\mathrm{Cr}(\mathrm{VI})$ removal at the initial $\mathrm{pH}$ within a range of 2-10 for $\mathrm{Cr}$ (VI) adsorption (Fig.9). Optimization studies for desorption of $\mathrm{Cr}$ (VI) from chitosan were carried out by means of a central composite design (CCD) using response surface methodology (RSM). A minimum level of speed (130 rpm), maximum levels of contact time $(81 \mathrm{~min})$ and desorption $(99.77 \%)$ were set for maximum desirability. Ramp desirability was generated using Design Expert 8.0.6.1.

\section{CONCLUSION}

From the experiments discussed above, the following conclusions can be drawn.

- The adsorption of Cr (VI) onto natural adsorbents has been examined. The comparative study showed that chitosan had the maximum adsorption capacity for $\mathrm{Cr}$ (VI).

- The Langmuir model has been found to be the most suitable with a maximum adsorption capacity of 35.7 $\mathrm{mg} / \mathrm{g}$ and a correlation coefficient, $\mathrm{R}^{2}=0.952$. The experimental data have been found to fit well with the pseudo second order kinetic model with $\mathrm{R}^{2}=0.999$.

- The energy of sorption was below $20.0 \mathrm{KJ} / \mathrm{mol}$ as per Dubinin-Radushkevich expression, confirms the adsorption was physisorption for all the cases studied.

- The experimental study results revealed that the rate of adsorption was controlled by adsorbent dosage; metal concentration and $\mathrm{pH}$ compared to other factors like shaking time and speed. Whereas optimization using Design Expert 8.0.6.1 software resulted metal concentration and $\mathrm{pH}$ as the most significant terms compared to other operating parameters.

- Chitosan is a best alternate to the conventional absorbents for wastewater treatment due to its high sorption capacity and regeneration character.

\section{SCOPE FOR FUTURE WORK}

Adsorption of heavy metals using natural adsorbents can be achieved in continuous multistage columns so 
that the technology can be transferred to industrial level.

$\checkmark$ Exact cost analysis can be done to find the economical adsorbent among the identified ones for heavy metal adsorption.

\section{ACKNOWLEDGEMENT}

This study was financially supported by DST, New Delhi (Project No: SR/FTP/CS-68/2007).

\begin{tabular}{|c|c|}
\hline & Nomenclature \\
\hline $\mathrm{C}_{\mathrm{in}}$ & $\mathrm{Cr}(\mathrm{VI})$ concentration in aqueous solutions before adsorption $(\mathrm{mg} / \mathrm{l})$ \\
\hline $\mathrm{C}_{\mathrm{o}}$ & $\mathrm{Cr}(\mathrm{VI})$ concentration in aqueous solutions after adsorption $(\mathrm{mg} / \mathrm{l})$ \\
\hline $\mathrm{B}$ & BET Constant \\
\hline $\mathrm{k}_{\mathrm{F}}$ & Freundlich constant \\
\hline $\mathrm{n}$ & Freundlich constant \\
\hline $\mathrm{K}_{\mathrm{L}}$ & Langmuir adsorption energy (L/mg). \\
\hline$q_{\max }$ & Monolayer adsorption capacity of adsorbent (mg/g), Langmuir \\
\hline $\mathrm{q}_{\mathrm{m}}$ & Maximum adsorption capacity (mg/g),BET \\
\hline $\mathrm{B}_{\mathrm{E}}$ & Free energy of sorption per mole of the sorbate \\
\hline $\mathrm{q}_{\mathrm{D}}$ & Dubinin-Radushkevich isotherm constant \\
\hline$\alpha$ & The initial adsorption rate $\left(\mathrm{mg} \cdot \mathrm{g}^{-1} \cdot \mathrm{min}^{-1}\right)$, Elovich Model \\
\hline$\beta$ & Desorption constant $\left(\mathrm{mg} \cdot \mathrm{g}^{-1} \cdot \mathrm{min}^{-1}\right)$, Elovich Model \\
\hline $\mathrm{q}_{\mathrm{T}}$ & Adsorption capacity at time $\mathrm{t}(\mathrm{mg} / \mathrm{g})$ \\
\hline $\mathrm{k}_{\text {int }}$ & Intra particle diffusion rate constant \\
\hline $\mathrm{m}$ & Weight of adsorbent $(\mathrm{g})$ \\
\hline $\mathrm{V}$ & Eluant volume (l) \\
\hline $\mathrm{C}_{\mathrm{f}}$ & Chromium concentration in synthetic eluant solution after desorption $(\mathrm{mg} / \mathrm{l})$ \\
\hline $\mathrm{y}$ & RSM response \\
\hline$\alpha_{0}$ & constant term \\
\hline$\alpha_{1}$ & The coefficients of the linear parameters, Adsorbent dosage (mg) \\
\hline$\alpha_{2}$ & The coefficients of the linear parameter, Metal Concentration $(\mathrm{mg} / \mathrm{l})$ \\
\hline$\alpha_{3}$ & The coefficients of the linear parameter,pH \\
\hline$\alpha_{1}^{2}$ & The coefficients of the quadratic parameter, Adsorbent dosage \\
\hline$\alpha_{2}{ }^{2}$ & The coefficients of the quadratic parameter, Metal Concentration \\
\hline$\alpha_{3}^{2}$ & The coefficients of the quadratic parameter, $\mathrm{pH}$ \\
\hline$\alpha_{1} \alpha_{2}$ & The coefficients of the interactive parameter \\
\hline$\varepsilon$ & The residual associated with the experiment \\
\hline $\mathrm{x}_{1}$ & coded values of the tests variables, Adsorbent dosage (mg) \\
\hline $\mathrm{x}_{2}$ & coded values of the tests variables, Metal Concentration $(\mathrm{mg} / \mathrm{l})$ \\
\hline $\mathrm{x}_{3}$ & coded values of the tests variables, $\mathrm{pH}$ \\
\hline
\end{tabular}

\section{REFERENCES}

[1]. Rajni K, Kesav K, Water Pollution: Management, Control and Treatment, 2010

[2]. Innocent Oboh, Emmanuel Aluyor and Thomas Audu, Leonardo Journal of Science[J], 2009,14:58.

[3]. Bielicka A, Bojanowska I and Wiśniewski A, Polish Journal of Environmental Studies[J], 2005,14(1):5.

[4]. Suranjana Arora Ray and Manas Kanti Ray, Al Ameen Journal of Medical Science[J], 2009,2(2): 57.

[5]. Tae Young Kim, Sun Kyu Park, SungYong Cho, Hwan Beom Kim, Yong Kang, Sang Done Kim and Seung Jai Kim, Korean Journal of Chemical Engineering [J],2005, 22(1): 91.

[6]. Varma A J, Deshpande S V and Kennedy J F, Carbohydrate Polymers[J],2004, 55(1) : 77

[7]. Jeon C, Park J Y and Yoo Y J, Korean Journal of Chemical Engineering[J], 2001,18(6):955.

[8]. Veglio F and Beolchini F, Hydrometallurgy[J], 1997,44 :301.

[9]. Alexeev V L, Kelberg E A, Qrd G A and Evmenenko, Polymer Engineering Science [J], 2000, 40(5):1211.

[10]. Luminita Balau, Gabriela Lisa, Popa M I, Tura V and Melnig V, Central European Journal of Chemistry[J], 2004,2(4):638.

[11]. Gardea Torresdey J L, De la Rosa G and Peralta Videa J R, Pure Applied Chemistry[J],2004,76(4):801.

[12]. Volesky B, Hydrometallurgy [J], 2000, 59(3) 203
[13]. Brown P A , Gill S A and Allen S J, Water Research[J], 2000,34(16):3907.

[14]. Ahalya N, Ramachandra T V and Kanamadi R.D, Research journal of Chemistry and Environment [J], 2003,7(4):71.

[15]. Kailas L Wasewar, IJRRAS[J], 2010,3 (3):303.

[16]. Malkoc E and Nuhoglu Y, Journal of Hazardous Materials[J], 2006,135:328.

[17]. Saroj S Baral ,Surendra N Dasa and Pradip Rath, Biochemicla Engineering Journal[J],2006,31(3):216.

[18]. Qaiser S, Saleemi A R and Umar M, Electronic Journal of Biotechnology[J], 2009,12 (4):1.

[19]. Russell V Lenth, Response-Surface Methods in Research, Using RSM, 2010.

[20]. Box G E P and Draper N R, Empirical Model-building and Response Surfaces (John Wiley \& Sons, New York), 1987.

[21]. Subhashini Ghorai and Pant K K , Sepration Purification Technology[J], 2005,42:265.

[22]. Wan Ngah W S, Kamari A and Koay Y J, International Journal of Biology and Macromolecule[J], 2004,38 :43.

[23]. Amanollah Ebadi, Jafar S Soltan Mohammad zadeh and Anvar Khudiev, Adsorption[J],2009,15:65.

[24]. Gholamreza Moussavi and Behnam barikbin, Chemical Engineering [J], 2010, 162:893.

[25]. Deniz caparkaya and Levent cavas, Acta chim slov [J], 2008,55 $: 547$. 
[26]. Ada K,Ergene S Tan and Yalcin E, Journal of Hazardous Material[J], 2009,165: 637

[27]. Shokoohi R, Saghi M H, Ghafari H R and Hadi M, Iran Journal of Environ Health Science Engineering[J],2009,6(2):107.

[28]. Alkan M , Demirbaş O and Dogan M , Microporous Mesoporous Materials[J], 2007,101(3):388.

[29]. Hui QIU, Lu LV, Bing-cai PAN, Qing-jian ZHANG, Wei-ming ZHANG and Quan-xing ZHANG, Journal of Zhejiang University Science[J], 2009,10(5):716.

[30]. Han R, Zou W, Yu W, Cheng S, Wang Y and Shi J, Journal of Hazardous Materials[J], 2007,141(1):156.

[31]. Hima Karnika Alluri, Srinivasa Reddy Ronda, Vijaya Saradhi Settalluri, Jayakumar, Singh Bondili, Suryanarayana V and Venkateshwar P, African Journal of Biotechnology[J],2007,6 (25):2924.

\section{Table Captions}

TABLE.1 ADSORPTION ISOTHERM MODELS

TABLE. 2 ADSORPTION KINETIC MODELS

TABLE 3 ISOTHERM PARAMETERS FOR CR (VI) ADSORPTION ONTO NATURAL ADSORBENTS

TABLE 4 KINETIC PARAMETERS FOR CR (VI) ADSORPTION

TABLE 5 INTRA PARTICLE DIFFUSION COEFFICIENTS FOR CR (VI) ADSORPTION

TABLE 6 THERMODYNAMIC PARAMETERS FOR ADSORPTION OF CR (VI) ONTO CHITOSAN

TABLE 7 ANOVA TEST FOR \% METAL REMOVAL USING THE CENTRAL COMPOSITE DESIGN , A, Jabibollah Y, Nader B, All A Z L, Farshid G, Ali D and Mazyar S, Journal of Hazardous matrials[J],2008,154: 694.

33]. Saifuddin M N and Kumaran P, Electronic Journal of Biotechnology[J],2005, 8(1).

34]. Schmuhl R, Krieg H M and Keizer K, Water Science, Technology and Engineering[J], 2001,27(1).

Sesinco, Eric Guibal, Jean Roussy and Pierrele Cloirec, Mineral Processing and Extractive Metallurgy Review [J],1998, 19: 277.

( Olalekan A Popoola and Vincent O Oninla, Pacific Journal of Science and Technology[J], 2009,10 (1)

37]. Bhuvaneshwari S, Sruthi D, Sivasubramanian V and Kanthimathy K, Journal of Science and Industrial Research[J],2012, 71:266.

TABLE.1 ADSORPTION ISOTHERM MODELS

\begin{tabular}{|c|c|c|c|}
\hline Isotherm & Linear form & Plot & Inference \\
\hline Langmuir & $\frac{1}{q_{e}}=\frac{1}{k_{L} q_{\max }}\left(\frac{1}{C_{e}}\right)+\frac{1}{q_{\max }}$ & $\frac{1}{\mathrm{q}_{\mathrm{e}}} v s \frac{1}{\mathrm{C}_{\mathrm{e}}}$ & $\begin{array}{l}\text { Monolayer adsorption can } \\
\text { only occur at a fixed number } \\
\text { of definite localized sites, that } \\
\text { are identical and equivalent. } \\
\text { Langmuir isotherm refers to } \\
\text { homogeneous adsorption }\end{array}$ \\
\hline Freundlich & $\ln \mathrm{q}_{\mathrm{e}}=\ln \mathrm{k}_{\mathrm{F}}+\frac{1}{\mathrm{n}} \ln \mathrm{C}_{\mathrm{e}}$ & $\ln \mathrm{q}_{\mathrm{e}} v s \ln \mathrm{C}_{\mathrm{e}}$ & $\begin{array}{l}\text { The stronger binding sites are } \\
\text { occupied first and that the } \\
\text { binding strength decreases } \\
\text { with increasing degree of site } \\
\text { occupation. }\end{array}$ \\
\hline $\begin{array}{l}\text { Brunauer- } \\
\text { Emmett } \\
\text { Teller }\end{array}$ & $\frac{\mathrm{C}_{\mathrm{e}}}{\left[\left(\mathrm{C}_{0}-\mathrm{C}_{\mathrm{e}}\right) \mathrm{q}_{\mathrm{e}}\right]}=\frac{1}{\mathrm{~Bq}_{\mathrm{m}}}+\frac{\mathrm{B}-1}{\mathrm{~Bq}_{\mathrm{m}}} \frac{\mathrm{C}_{\mathrm{e}}}{\mathrm{C}_{0}}$ & $\frac{\mathrm{C}_{\mathrm{e}}}{\left[\left(\mathrm{C}_{0}-\mathrm{C}_{\mathrm{e}}\right) \mathrm{q}_{\mathrm{e}}\right]} v s \frac{\mathrm{C}_{\mathrm{e}}}{\mathrm{C}_{0}}$ & $\begin{array}{l}\text { Multilayer adsorptions with } \\
\text { the following hypotheses: (a) } \\
\text { molecules physically adsorb } \\
\text { on a solid in layers infinitely; } \\
\text { (b) there is no interaction } \\
\text { between each adsorption layer. } \\
\text { Explain the physical } \\
\text { adsorption of molecules } \\
\text { on a solid surface and basis for } \\
\text { the measurement of specific } \\
\text { surface area of a material. }\end{array}$ \\
\hline $\begin{array}{c}\text { Dubinin- } \\
\text { Radushkevich }\end{array}$ & $\ln \left(\mathrm{q}_{\mathrm{e}}\right)=\ln \left(\mathrm{q}_{\mathrm{d}}\right)-\mathrm{B}_{\mathrm{E}}\left[\mathrm{RT} \ln \left(1+\frac{1}{\mathrm{Ce}}\right)\right]^{2}$ & $\begin{array}{l}\ln \mathrm{q}_{\mathrm{e}} \mathrm{VS} \\
\left.\left[\mathrm{RT} \ln 1+1 / \mathrm{C}_{\mathrm{e}}\right)\right]^{2}\end{array}$ & $\begin{array}{l}\text { The constant } \mathrm{B}_{\mathrm{E}} \text { gives an idea } \\
\text { about the mean free energy } \mathrm{E} \text {. } \\
\mathrm{It} \text { is parameter used in } \\
\text { predicting the type of } \\
\text { adsorption. An } \mathrm{E} \text { value }<8 \\
\mathrm{kJmol} \text { is an indication of } \\
\text { physisorption ,a value in } \\
\text { between } 8 \text { and } 16 \mathrm{~kJ} \text { mol } \\
\text { indicates ion exchange and if } \\
\text { E } 20 \text { kJ it } \\
\text { chemisorptions }\end{array}$ \\
\hline
\end{tabular}


International Advanced Research Journal in Science, Engineering and Technology

Vol. 2, Issue 8, August 2015

TABLE.2 ADSORPTION KINETIC MODELS

\begin{tabular}{|c|c|c|c|}
\hline Isotherm & Linear Form & Plot & Inference \\
\hline $\begin{array}{c}\text { Pseudo } \\
\text { first order }\end{array}$ & $\log \left(q_{e}-q_{t}\right)=\log q_{e}-k_{1} \frac{t}{2.303}$ & $\begin{array}{l}\log \left(q_{e}-q_{t}\right) \\
\text { vs t }\end{array}$ & $\begin{array}{l}\text { It is only an approximate solution to } \\
\text { the first order rate mechanism. The } \\
\text { parameter } \log (\mathrm{qe}) \text { is an adjustable } \\
\text { parameter and it is not often equal to } \\
\text { the intercept of a plot of } \log (\mathrm{qe}-\mathrm{qt}) \\
\text { against t, whereas in a true first } \\
\text { order system, } \log (\mathrm{qe}) \text { should be } \\
\text { equal to the intercept of a plot. } \\
\text { Describe the adsorption rate based } \\
\text { on the adsorption capacity. }\end{array}$ \\
\hline $\begin{array}{c}\text { Pseudo } \\
\text { second order }\end{array}$ & $\frac{\mathrm{t}}{\mathrm{q}_{\mathrm{t}}}=\frac{1}{\mathrm{k}_{2} \mathrm{q}_{\mathrm{e}}^{2}}+\frac{\mathrm{t}}{\mathrm{q}_{\mathrm{e}}}$ & $\left(t / q_{t}\right) v s . t$ & $\begin{array}{l}\text { Film diffusion might be involved in } \\
\text { the sorption process. }\end{array}$ \\
\hline Elovich model & $q=\left(\frac{1}{\beta}\right) \ln (\alpha \beta)+\left(\frac{1}{\beta}\right) \ln t$ & $\mathrm{q} v \mathrm{~s} \ln \mathrm{t}$ & $\begin{array}{l}\text { The Elovich kinetic equation is } \\
\text { based on adsorption capacity, The } \\
\text { rate of adsorption } \\
\text { of solute on adsorbent decrease } \\
\text { exponentially with an increase in the } \\
\text { amount of solute adsorbed. }\end{array}$ \\
\hline $\begin{array}{l}\text { Intra particle } \\
\text { diffusion }\end{array}$ & $\mathrm{q}_{\mathrm{t}}=\mathrm{k}_{\mathrm{int}} \mathrm{t}^{1 / 2}$ & $q_{t} v^{1 / 2} t^{1 / 2}$ & $\begin{array}{l}\text { For Weber-Morris model, It is } \\
\text { essential for the } q_{t} \text { vs } t \text { plot to go } \\
\text { through the origin, if the intra } \\
\text { particle diffusion is the sole rate- } \\
\text { limiting step. However, it is not } \\
\text { always the case and adsorption } \\
\text { kinetics may be controlled by film } \\
\text { diffusion and intra particle diffusion } \\
\text { simultaneously. Thus, the slope is } \\
\text { not equal to zero }\end{array}$ \\
\hline
\end{tabular}

TABLE 3 ISOTHERM PARAMETERS FOR CR (VI) ADSORPTION ONTO NATURAL ADSORBENTS

\begin{tabular}{|c|c|c|c|c|}
\hline Isotherm & Adsorbent & \multicolumn{3}{|c|}{ Isotherm parameters } \\
\hline \multirow{3}{*}{ Langmuir } & Chitosan & $\mathrm{q}_{\max }=35.7 \mathrm{mg} / \mathrm{g}$ & $\mathrm{K}_{\mathrm{L}}=4 \mathrm{~L} / \mathrm{mg}$ & $\mathrm{R}^{2}=0.952$ \\
\cline { 2 - 5 } & Saw dust & $\mathrm{q}_{\max }=0.995 \mathrm{mg} / \mathrm{g}$ & $\mathrm{K}_{\mathrm{L}}=0.024 \mathrm{~L} / \mathrm{mg}$ & $\mathrm{R}^{2}=0.626$ \\
\cline { 2 - 5 } & Tea waste & $\mathrm{q}_{\max }=4.5 \mathrm{mg} / \mathrm{g}$ & $\mathrm{K}_{\mathrm{L}}=0.13$ & $\mathrm{R}^{2}=0.865$ \\
\hline \multirow{3}{*}{ Freundlich } & Chitosan & $\mathrm{k}_{\mathrm{F}}=29.4$ & $\mathrm{n}=1.87$ & $\mathrm{R}^{2}=0.940$ \\
\cline { 2 - 5 } & Saw dust & $\mathrm{k}_{\mathrm{F}}=0.027$ & $\mathrm{n}=1.195$ & $\mathrm{R}^{2}=0.860$ \\
\cline { 2 - 5 } & Tea waste & $\mathrm{k}_{\mathrm{F}}=0.66$ & $\mathrm{n}=0.79$ & $\mathrm{R}^{2}=0.923$ \\
\hline \multirow{3}{*}{ BET } & Chitosan & $\mathrm{q}=24.5 \mathrm{mg} / \mathrm{g}$ & $\mathrm{B}=38.04$ & $\mathrm{R} 2=0.922$ \\
\cline { 2 - 5 } & Saw dust & $\mathrm{q}=0.018 \mathrm{mg} / \mathrm{g}$ & $\mathrm{B}=-1.81$ & $\mathrm{R} 2=0.821$ \\
\cline { 2 - 5 } & Tea waste & $\mathrm{q}=1.515 \mathrm{mg} / \mathrm{g}$ & $\mathrm{B}=3.235$ & $\mathrm{R} 2=0.695$ \\
\hline
\end{tabular}

TABLE 4 KINETIC PARAMETERS FOR CR (VI) ADSORPTION

\begin{tabular}{|c|c|c|c|c|c|c|c|c|c|c|}
\hline & \multicolumn{4}{|c|}{ Pseudo first order } & \multicolumn{3}{|c|}{ Pseudo second order } & \multicolumn{3}{|c|}{ Elovich } \\
\hline Adsorbent & $\begin{array}{c}\mathrm{q}_{\mathrm{e}} \\
\exp \\
(\mathrm{mg} / \mathrm{g})\end{array}$ & $\begin{array}{c}\mathbf{q}_{\mathrm{e}} \\
\text { calculated } \\
(\mathrm{mg} / \mathrm{g})\end{array}$ & $\begin{array}{c}\mathbf{k}_{1} \\
\left(\mathbf{m i n}^{-}\right. \\
\left.\mathbf{1}^{-}\right)\end{array}$ & $\mathbf{R}^{2}$ & $\begin{array}{c}\mathrm{q}_{\mathrm{e}} \\
\text { calculated } \\
(\mathrm{mg} / \mathrm{g})\end{array}$ & $\begin{array}{c}\mathrm{k}_{2} \\
\left(\mathrm{~min}^{-1}\right. \\
\left.\text { g. } \mathrm{mg}^{-1}\right)\end{array}$ & $\mathbf{R}^{2}$ & $\begin{array}{c}\beta \\
(\text { g.mg } \\
-1\end{array}$ & $\begin{array}{c}\alpha \\
\left(\mathrm{min}^{-1}\right. \\
\left.\text { g.mg }^{-1}\right)\end{array}$ & $\mathbf{R}^{2}$ \\
\hline Chitosan & 5.95 & 0.99 & 0.017 & 0.764 & 6.06 & 0.074 & 0.999 & 5.076 & $2.2 \times 10^{10}$ & 0.888 \\
\hline Saw dust & 0.094 & 0.022 & 0.020 & 0.545 & 0.094 & 2.943 & 0.999 & 357.1 & $2.5 \times 10^{9}$ & 0.956 \\
\hline Tea waste & 0.522 & 0.044 & 0.021 & 0.940 & 0.526 & 1.050 & 0.999 & 100 & $1.9 \times 10^{18}$ & 0.978 \\
\hline
\end{tabular}


International Advanced Research Journal in Science, Engineering and Technology Vol. 2, Issue 8, August 2015

TABLE 5 INTRA PARTICLE DIFFUSION COEFFICIENTS FOR CR (VI) ADSORPTION

\begin{tabular}{|c|c|c|c|c|c|}
\hline System/ Adsorbent & $\mathbf{t}$ & $\mathbf{q}_{\mathrm{t}}$ & $\mathrm{t}^{0.5}$ & $\mathbf{K}_{\text {id }}$ & $\mathbf{R}^{2}$ \\
\hline \multirow[t]{6}{*}{ Chitosan } & 20 & 5.64 & 4.47 & \multirow[t]{6}{*}{0.062} & \multirow[t]{6}{*}{0.935} \\
\hline & 40 & 5.709 & 6.32 & & \\
\hline & 60 & 5.761 & 7.74 & & \\
\hline & 80 & 5.925 & 8.94 & & \\
\hline & 90 & 5.949 & 9.48 & & \\
\hline & 100 & 5.949 & 10 & & \\
\hline \multirow[t]{7}{*}{ Saw dust } & 30 & 5.477 & 0.074 & \multirow[t]{7}{*}{0.002} & \multirow[t]{7}{*}{0.908} \\
\hline & 60 & 7.745 & 0.078 & & \\
\hline & 120 & 10.954 & 0.093 & & \\
\hline & 180 & 13.416 & 0.0945 & & \\
\hline & 240 & 15.491 & 0.0955 & & \\
\hline & 300 & 17.32 & 0.0985 & & \\
\hline & 360 & 18.973 & 0.101 & & \\
\hline \multirow[t]{8}{*}{ Tea waste } & 30 & 3.16 & 0.552 & \multirow[t]{8}{*}{0.023} & \multirow[t]{8}{*}{0.972} \\
\hline & 60 & 4.47 & 0.559 & & \\
\hline & 90 & 5.47 & 0.566 & & \\
\hline & 120 & 6.32 & 0.575 & & \\
\hline & 150 & 7.07 & 0.587 & & \\
\hline & 180 & 7.74 & 0.591 & & \\
\hline & 210 & 8.36 & 0.593 & & \\
\hline & 240 & 8.94 & 0.593 & & \\
\hline
\end{tabular}

TABLE 6 THERMODYNAMIC PARAMETERS FOR ADSORPTION OF CR (VI) ONTO CHITOSAN

\begin{tabular}{|c|c|c|c|c|c|}
\hline $\begin{array}{c}\text { Temperature } \\
\left({ }^{\circ} \mathrm{C}\right)\end{array}$ & $K=\frac{C_{a}}{C_{e}}$ & $\ln K$ & $\Delta G=-R T \ln K$ & $\begin{array}{c}\Delta H \\
\mathrm{~J} / \mathrm{mol}\end{array}$ & $\begin{array}{c}\Delta S \\
\mathrm{~J} / \mathrm{mol} \mathrm{K}\end{array}$ \\
\hline 30 & 0.979 & -0.021 & 52.90 & & \multirow{2}{*}{-6699.42} \\
\hline 40 & 0.973 & -0.027 & 70.26 & -22.115 \\
\hline 50 & 0.993 & -0.23 & 617.64 & \\
\hline 60 & 0.78 & -0.22 & 609.08 & & \\
\hline
\end{tabular}

TABLE 7 ANOVA TEST FOR \% METAL REMOVAL USING THE CENTRAL COMPOSITE DESIGN

\begin{tabular}{|c|c|c|c|c|c|c|}
\hline Model term & Coefficient estimate & Sum of square & Mean square & DF & F-Value & P-Value \\
\hline$\alpha_{0}$ Intercept & +99.20 & 388.27 & 55.47 & 7 & 35.52 & $<0.001$ \\
\hline $\begin{array}{c}\alpha_{1} \text { Adsorbent } \\
\text { dosage }\end{array}$ & -117.73 & 0.46 & 0.46 & 1 & 0.30 & 0.5958 \\
\hline $\begin{array}{c}\alpha_{2} \text { Metal } \\
\text { concentration }\end{array}$ & -11.74 & 98.18 & 98.18 & 1 & 62.87 & $<0.001$ \\
\hline$\alpha_{3} \mathrm{pH}$ & +36.313 & 117.68 & 117.68 & 1 & 75.35 & $<0.001$ \\
\hline$\alpha_{1}^{2}$ & +5.77 & 0.35 & 0.35 & 1 & 0.22 & 0.6448 \\
\hline$\alpha_{2}{ }^{2}$ & -0.229 & 9.22 & 9.22 & 1 & 5.91 & 0.0317 \\
\hline$\alpha_{3} 2$ & -4.049 & 180.61 & 180.61 & 1 & 115.65 & $<0.001$ \\
\hline$\alpha_{1} \alpha_{2}$ & +18.28 & 122.04 & 122.04 & 1 & 78.15 & $<0.001$ \\
\hline Residual & - & 18.74 & 1.56 & 12 & - & - \\
\hline $\begin{array}{l}\text { Std. Dev. } \\
\text { Mean } \\
\text { C.V. \% } \\
\text { R-Squared } \\
\text { Adeq Precision }\end{array}$ & $\begin{array}{ll}: & 1.25 \\
: & 96.72 \\
: & 1.29 \\
: & 0.954 \\
: & 24.112\end{array}$ & & & & & \\
\hline
\end{tabular}




\section{Figure captions}

Fig.1 Effect of $\mathrm{pH}$, adsorbent dosage , contact time and $\mathrm{Cr}(\mathrm{VI})$ concentration on $\mathrm{Cr}(\mathrm{VI})$ adsorption on chitosan Fig.2 Isotherm plot for adsorption Cr (VI) onto chitosan at different temperature (Langmuir, Freundlich \& BET)

Fig.3 Kinetics plot for adsorption Cr (VI) onto chitosan (Pseudo first order, Pseudo second order, Elovich and Intra particle diffusion model)

Fig.4 Effect of adsorbent dosage, pH \& contact time on $\mathrm{Cr}$ (VI) adsorption onto saw dust

Fig.5 Effect of adsorbent dosage, $\mathrm{pH}$, contact time and shaking speed on Cr (VI) adsorption onto tea waste

Fig.6 Dubinin- Radushkevich isotherm for adsorption Cr (VI) onto chitosan, saw dust and tea waste

Fig.7 Plot of $\ln \mathrm{K}$ versus 1/T for the adsorption of $\mathrm{Cr}$ (VI) onto chitosan

Fig.8 Response surface and contour plots for $\mathrm{Cr}(\mathrm{VI})$ adsorption capacity as a function of the test variables adsorbent dosage $\left(\mathrm{x}_{1}\right)$, metal concentration $\left(\mathrm{x}_{2}\right)$ and $\mathrm{pH}\left(\mathrm{x}_{3}\right)$

Fig.9 Desirability ramp for six goals - adsorbent dosage, metal concentration, $\mathrm{pH}$, agitation speed, shaking time and \% adsorption
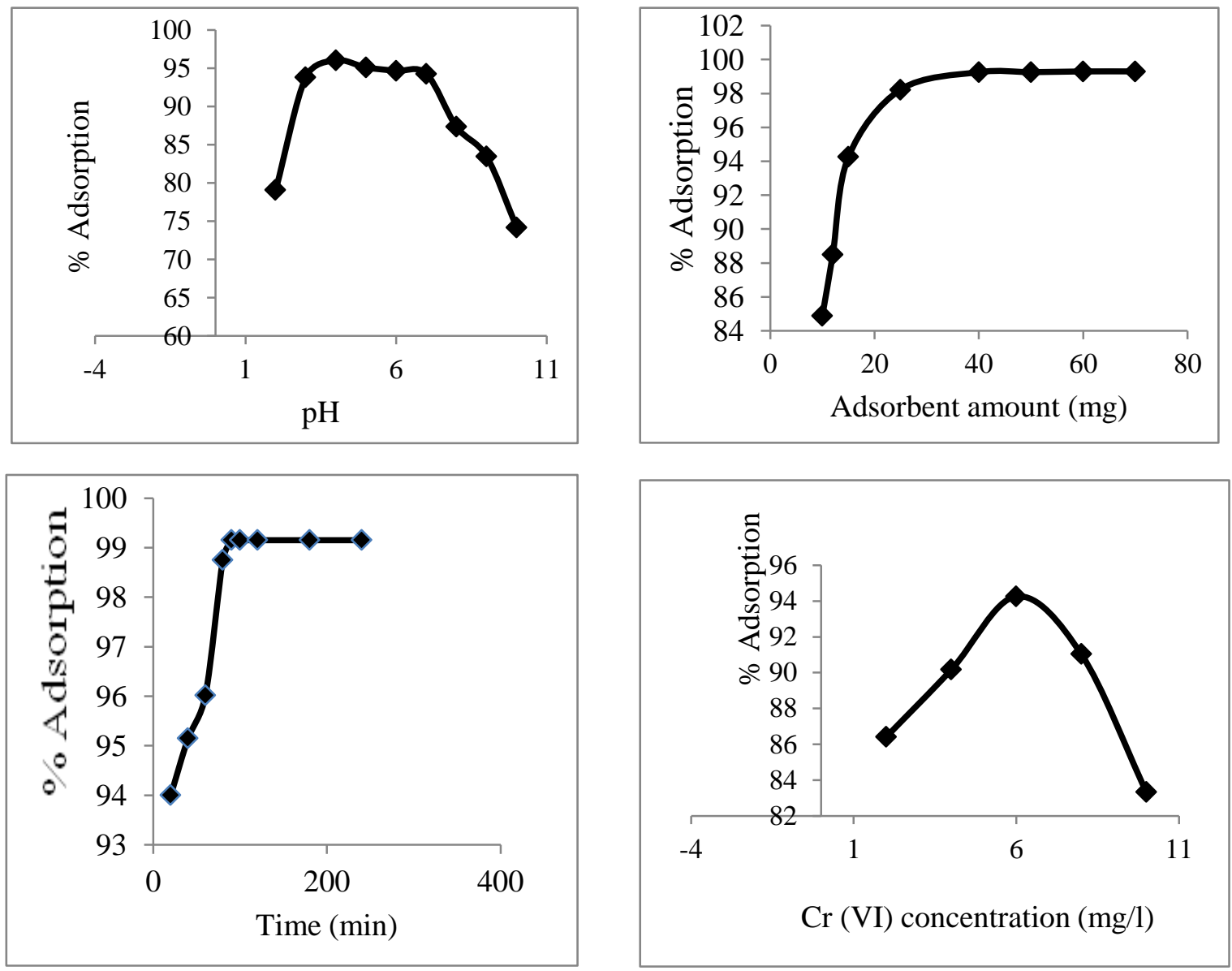

Fig.1 Effect of pH, adsorbent dosage, contact time and $\mathrm{Cr}(\mathrm{VI})$ concentration on $\mathrm{Cr}$ (VI) adsorption on chitosan

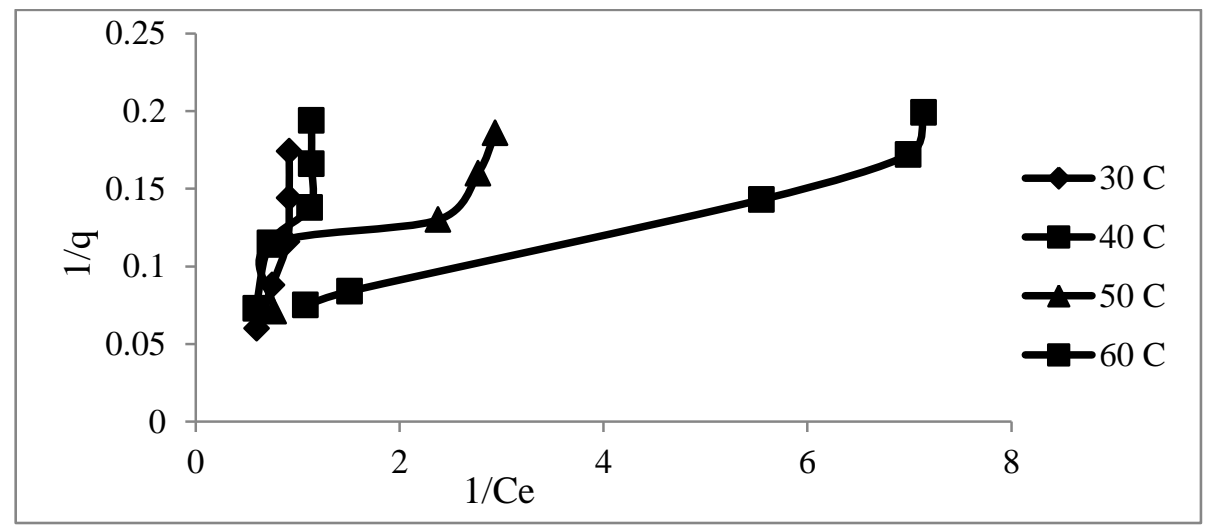



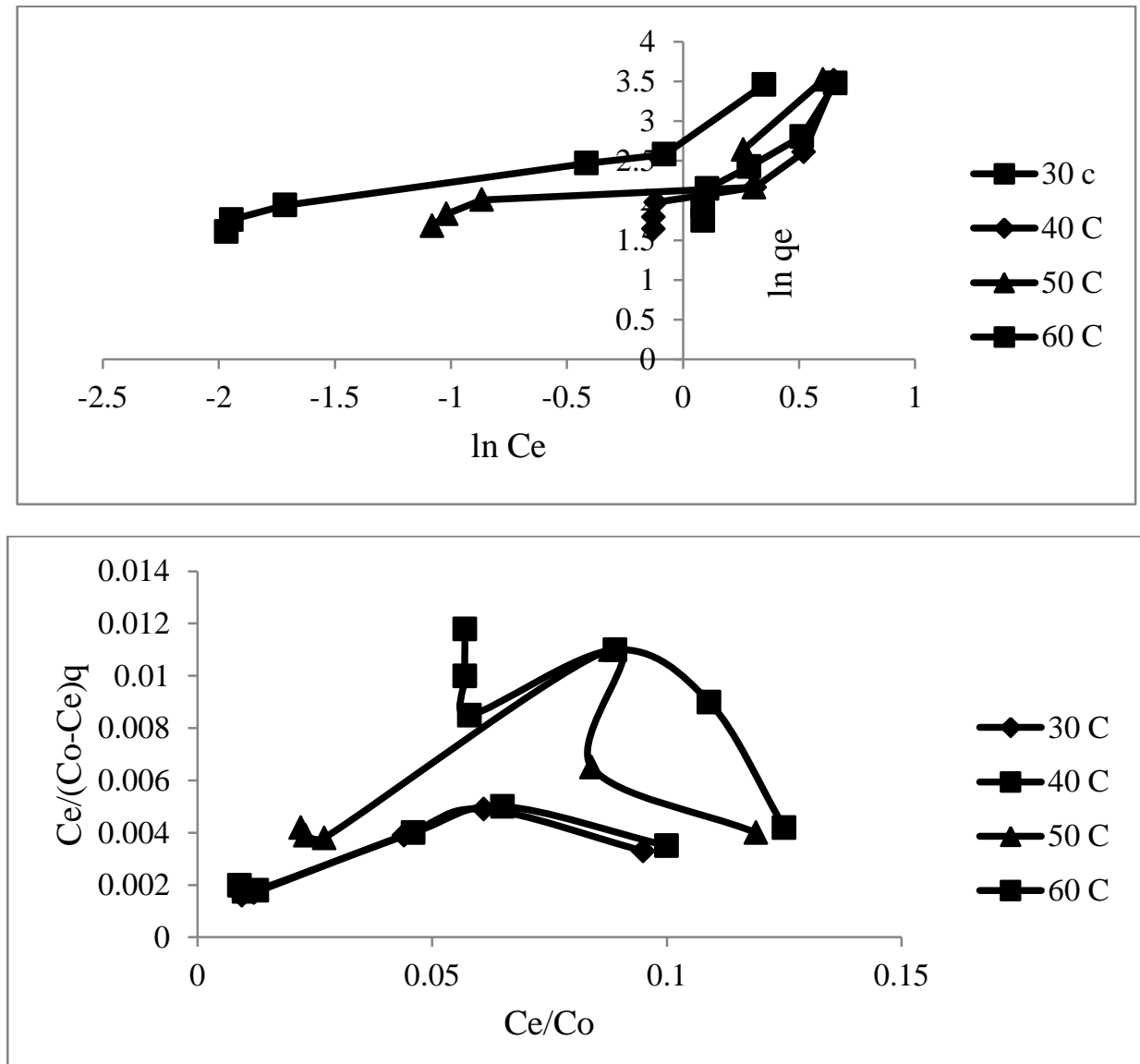

Fig.2 Isotherm plot for adsorption Cr (VI) onto chitosan at different temperature (Langmuir, Freundlich \& BET)
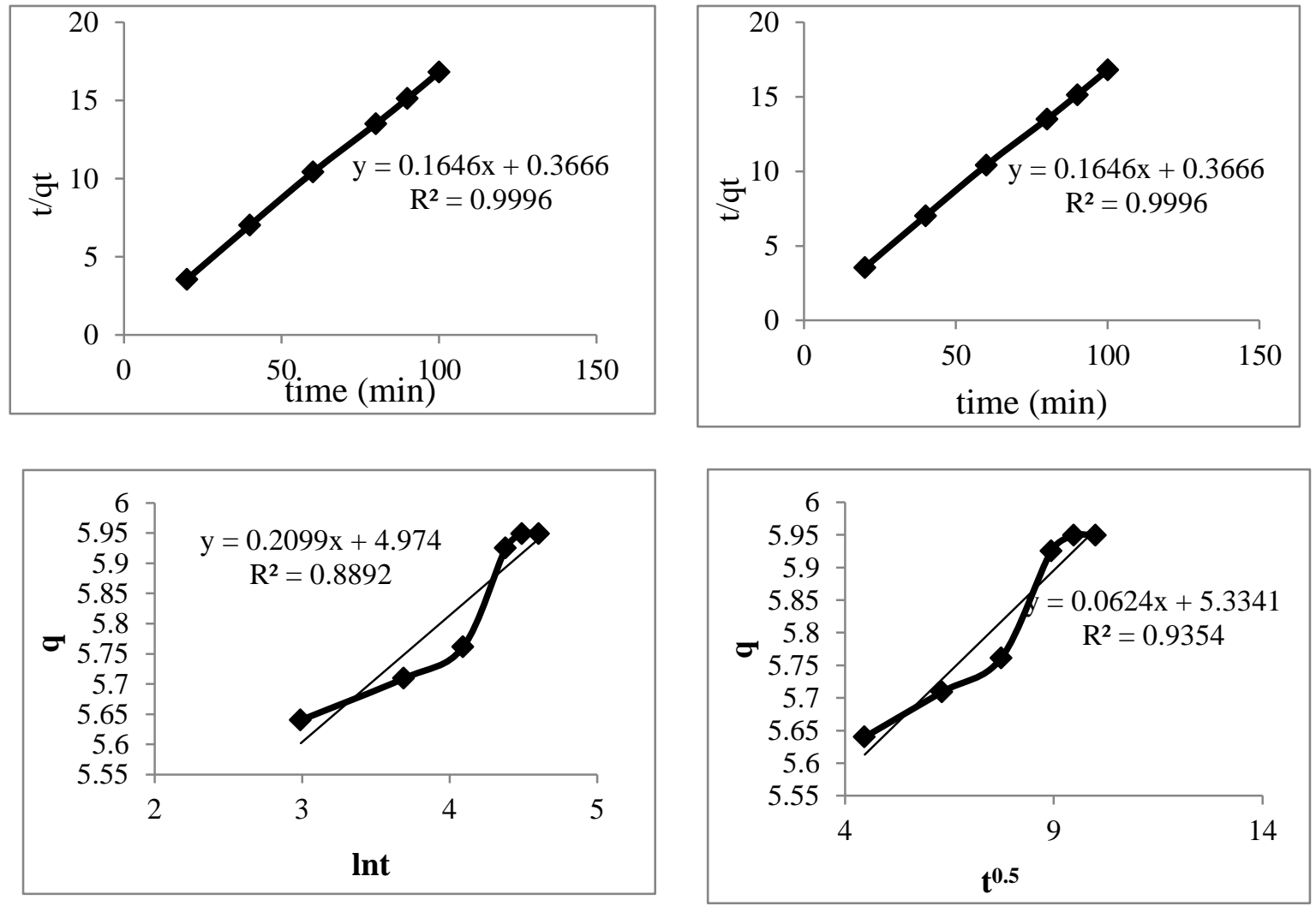

Fig.3 Kinetics plot for adsorption Cr (VI) onto chitosan (Pseudo first order, Pseudo second order, Elovich and Intra particle diffusion model) 

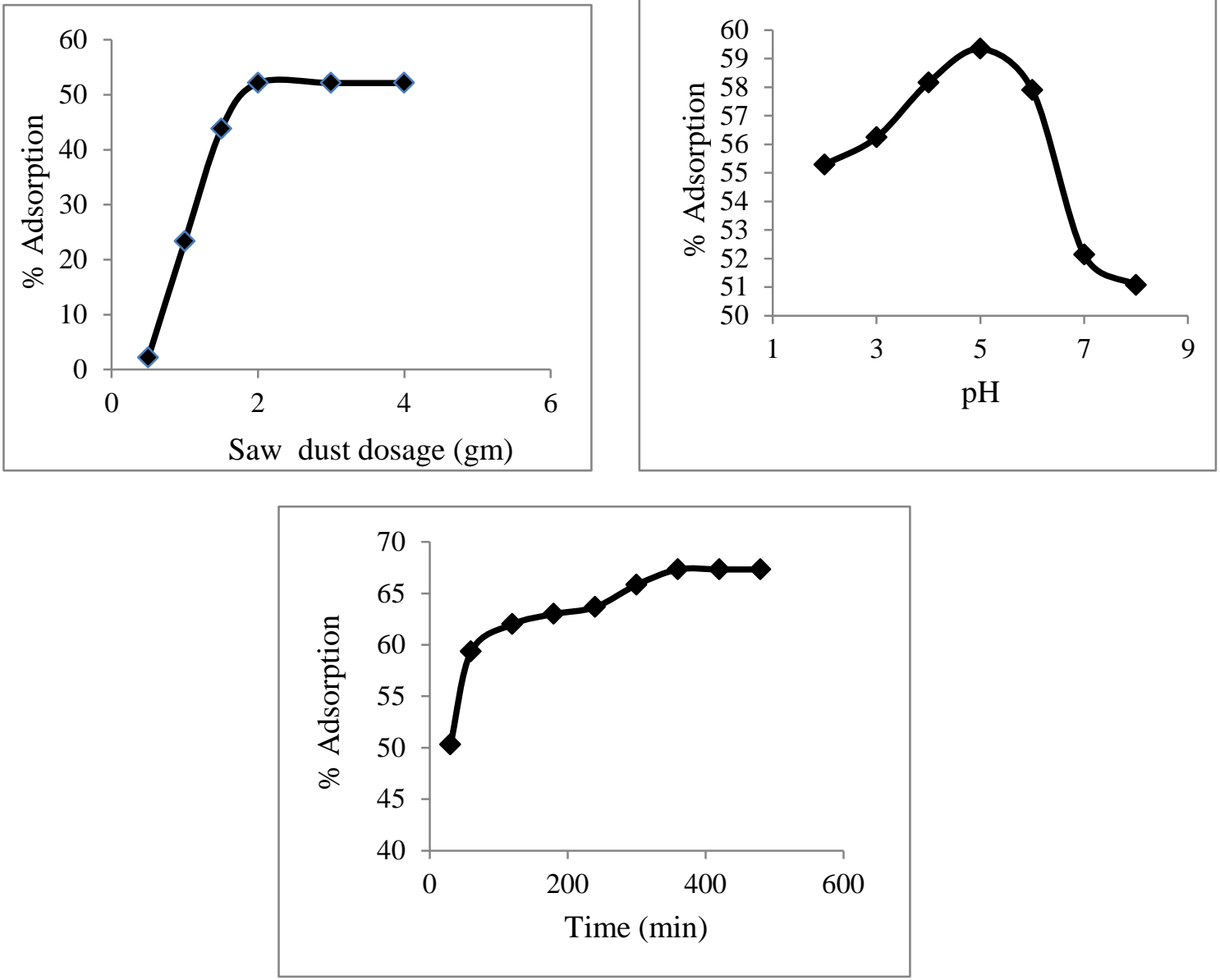

Fig.4 Effect of adsorbent dosage, $\mathrm{pH}$ \& contact time on $\mathrm{Cr}$ (VI) adsorption onto saw dust
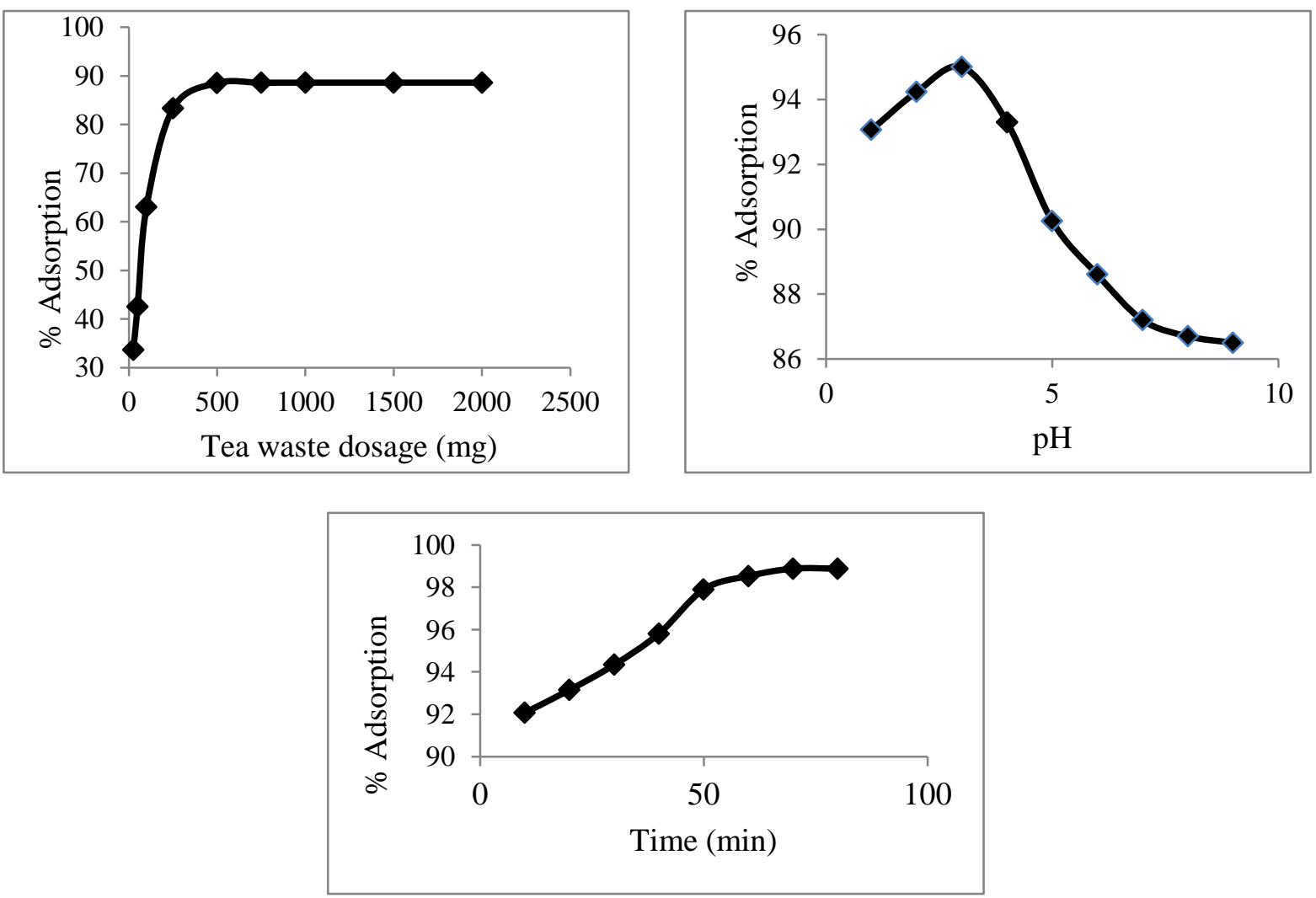

Fig.5 Effect of adsorbent dosage, $\mathrm{pH}$ \& contact time on $\mathrm{Cr}$ (VI) adsorption onto tea waste 
International Advanced Research Journal in Science, Engineering and Technology Vol. 2, Issue 8, August 2015
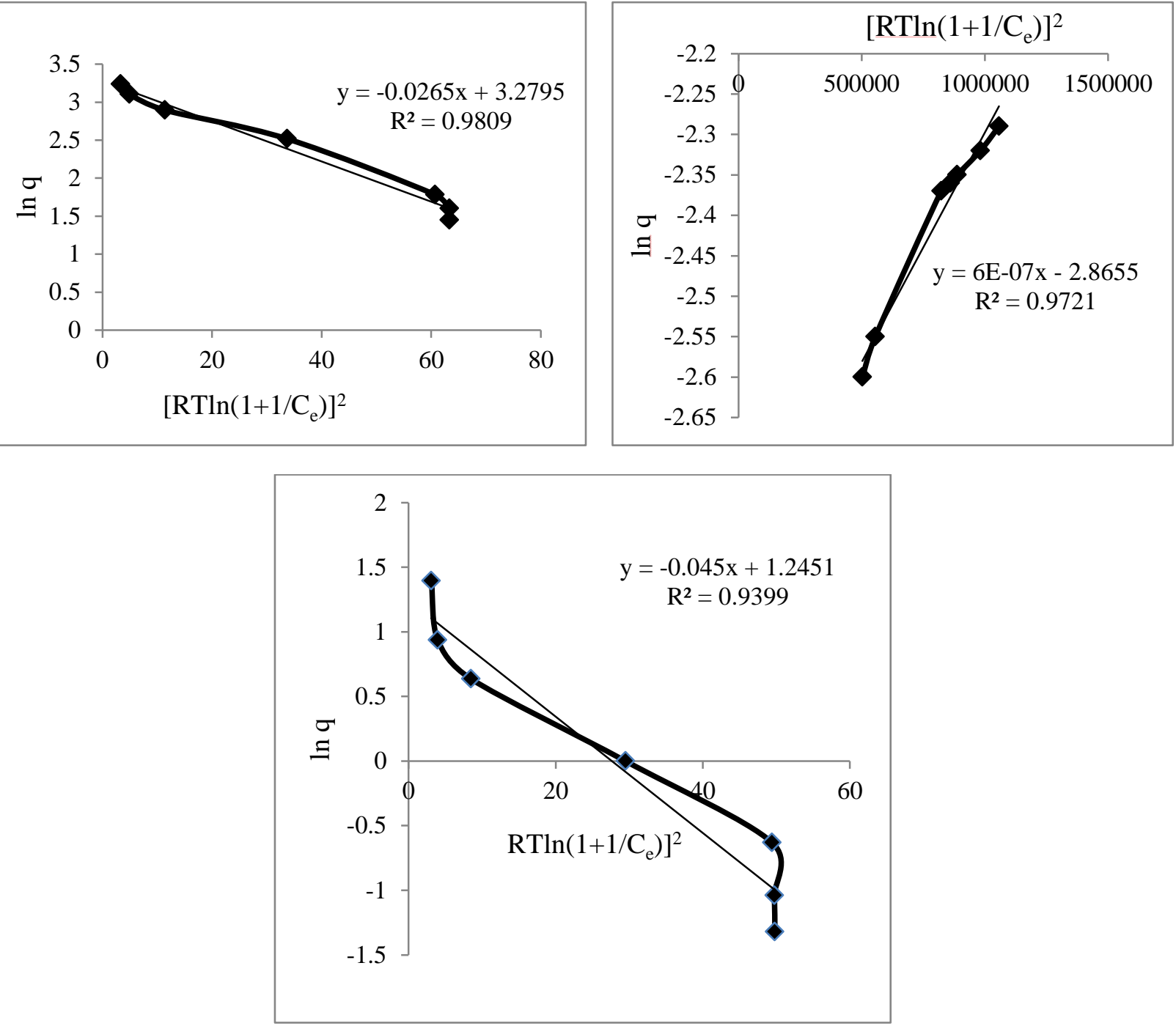

Fig.6 Dubinin- Radushkevich isotherm for adsorption Cr (VI) onto chitosan, saw dust and tea waste

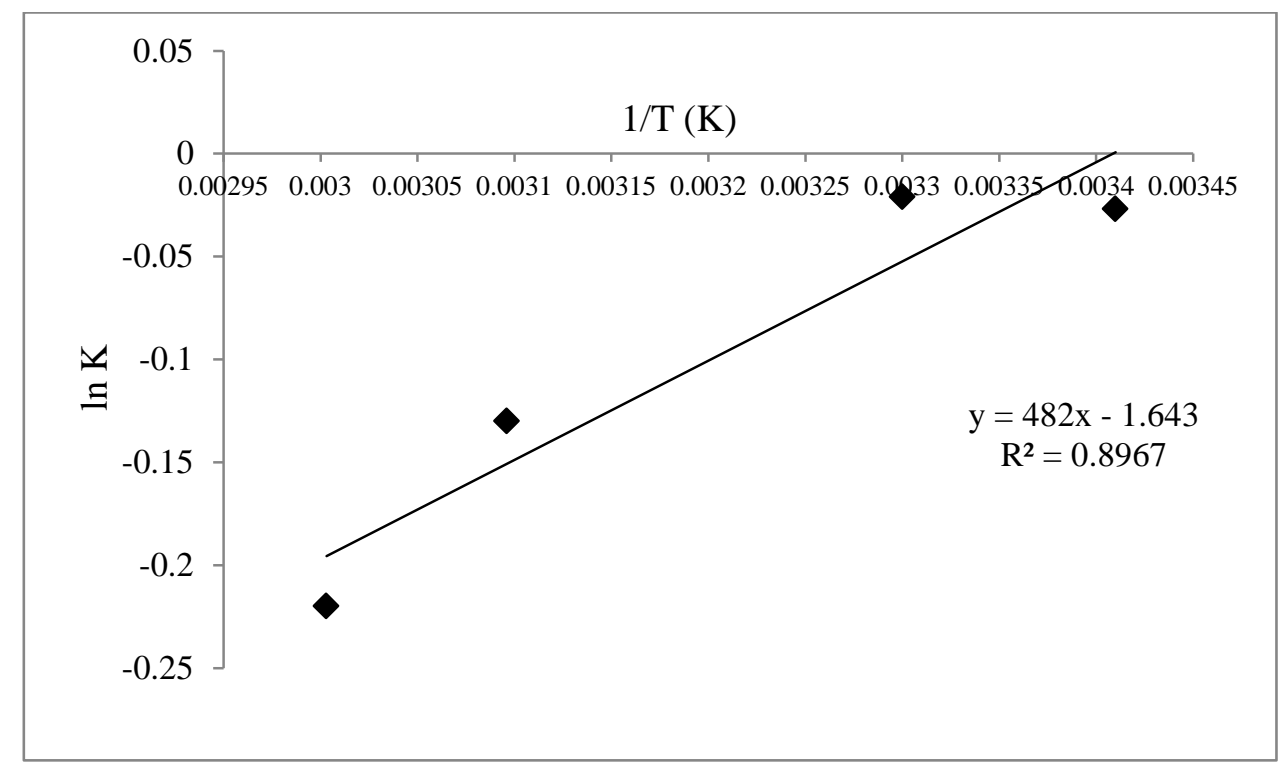

Fig.7 Plot of $\ln \mathrm{K}$ versus 1/T for the adsorption of $\mathrm{Cr}$ (VI) onto chitosan 


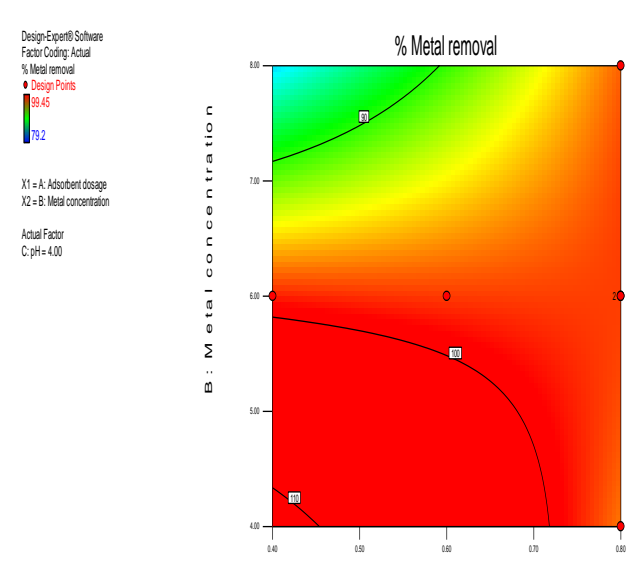

A: Assorbent dosage
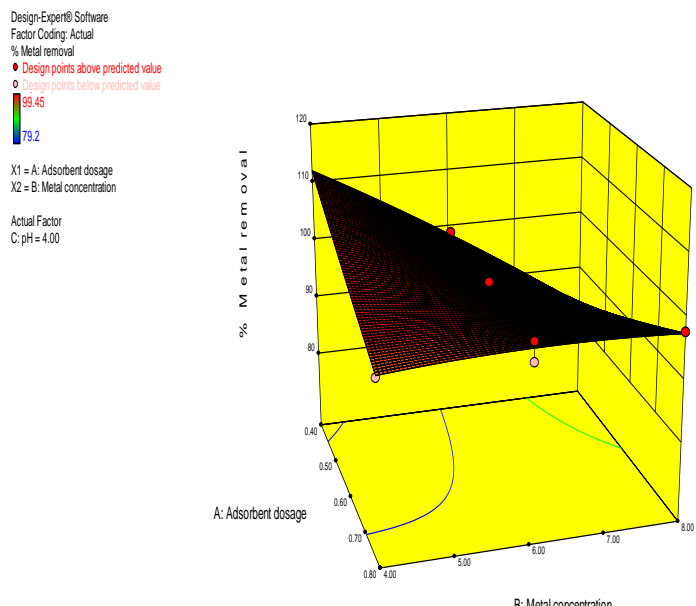

Fig.8 Response surface and contour plots for $\mathrm{Cr}(\mathrm{VI})$ adsorption capacity as a function of the test variables adsorbent dosage $\left(\mathrm{x}_{1}\right)$, metal concentration $\left(\mathrm{x}_{2}\right)$ and $\mathrm{pH}\left(\mathrm{x}_{3}\right)$.

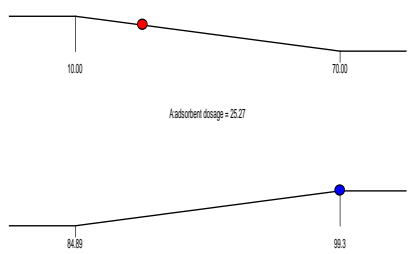

resanger 1993

Desiratily $=0.863$

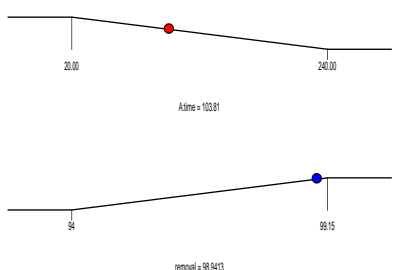

Desiatility $=0.71$
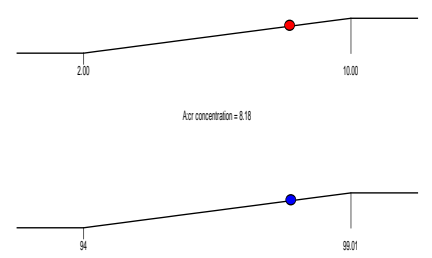

Desiraility $=0.74$

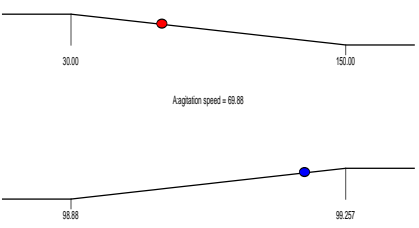

Desiadiliy 0.754

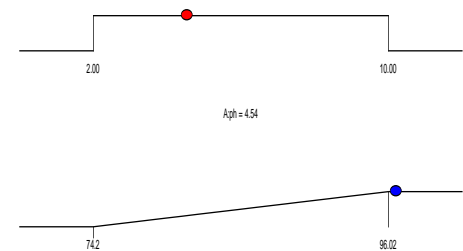

Fenoual 96.9695

Desiribility $=0.993$

Fig.9 Desirability ramp for six goals - adsorbent dosage, metal concentration, pH, agitation speed, shaking time and \% adsorption 